\title{
Author Correction: Aiming higher to bend the curve of biodiversity loss
}

Georgina M. Mace, Mike Barrett, Neil D. Burgess, Sarah E. Cornell, Robin Freeman, Monique Grooten and Andy Purvis

Correction to: Nature Sustainability https://doi.org/10.1038/s41893-018-0130-0, published online 14 September 2018.

In the version of this Comment originally published, the following sentence was not included in the Acknowledgements: "S.E.C. acknowledges part-funding from the European Research Council under the European Union's Horizon 2020 research and innovation programme (Earth Resilience in the Anthropocene, grant no. ERC-2016-ADG 743080)." It has now been added in all versions of the Comment.

Published online: 10 August 2020

https://doi.org/10.1038/s41893-020-00604-3

(C) Springer Nature Limited 2020 